\title{
Communication
}

\section{Trends of publications (1910-2020) on climate change/global warming/climate emergency versus general climate research}

\author{
Rafael M. Santos 1,*
}

Citation: Santos, R.M. Trends of publications (1910-2020) on climate change/global warming/climate emergency versus general climate research. Earth 2021, 2, FirstpageLastpage.

https://doi.org/10.3390/xxxxx

1.

\author{
1 School of Engineering, University of Guelph, Guelph, Ontario, Canada \\ * Correspondence: santosr@uoguelph.ca
}

\begin{abstract}
This article presents and discusses analytical data on the scientific publication record from 1910 to 2020 on two topics: "climate" and "climate change/global warming/climate emergency". The goal is to visualize how the publication record on these two topics has evolved over time, from different classification perspectives (year, country, source and organization). Three hypotheses are tested using data collected from Web of Science and various graphical representations of the data. It is found that research output related to the Earth's contemporary changing climate overtook that of general climate research in 2011, and the publication ratio has been expanding in the last decade. There are significant differences in the publication countries and sources between the two topics, and conversely less significant differences in terms of organizations publishing these works. Differentiation factors that affect the level of research output and engagement on the climate challenge include: island versus landlocked nations, specialized versus general scientific journals, academic versus institutional organizations. The future of the publication records is discussed, such as the emergence of new terms to refer to the climate challenge, such as "climate emergency".
\end{abstract}

Keywords: human influence on climate; natural control of climate; climatic and non-climatic effects on living organisms; improving climate monitoring; climate variability; climate models; $\mathrm{CO}_{2}$.

\section{Introduction}

Climate Change, Global Warming and more recently Climate Emergency (CC/GW/CE) have been, in the past decade and more, terms synonymous with the greatest sustainability challenge of the $21^{\text {st }}$ century [1-4]. In this article, we explore the publication trends since these terms appeared in the journal records, in the early part of the $20^{\text {th }}$ century, to test the following hypotheses:

It is possible to substantially distinguish the scientist literature that pertains to the study of the aforementioned climate challenge (or solutions for mitigating it) from studies that address gaining better understanding of the Earth's climate itself, using topical keyword searches.

The scientific literature has become so enriched in works addressing the climate challenge, that it surpassed climate research in terms of number of publications sometime in the late part of the $20^{\text {th }}$ century.

The scientific literature that pertains to the climate challenge is at least partly distinct from that on climate research, in terms of venue of publication, country of origin of studies, and organizations that have conducted these works.

\section{Methodology}

Web of Science (WoS) was used to search the scientific literature and collect the relevant publication data for analysis. The search was conducted on October $20^{\text {th }}, 2020$, and all data were collected within a short time that day, to obtain a snapshot of the publication record. The search used a timespan of 1900 to 2020 and all indexes within the Web of 
Science Core Collection, namely: SCI-EXPANDED (1900-2020), SSCI (1900-2020), A\&HCI (1975-2020), CPCI-S (1990-2020), CPCI-SSH (1990-2020) and ESCI (2015-2020). The two search strings used were: (i) TOPIC: ("climate change" OR "global warming" OR "climate emergency"); and (ii) TOPIC: ("climate" NOT ("climate change" OR "global warming" OR "climate emergency")). The former search string was used to collect papers related to research on the climate challenge $(\mathrm{CC} / \mathrm{GW} / \mathrm{CE})$, and the latter search string was used to collect papers related to general research on the Earth's climate (CL). That is, these search strings tested Hypothesis 1 . The searchers were further refined to document type 'Article'. These searches yield 219,830 on the CC/GW/CE topic, and 231,016 papers on the CL topic. The use of the NOR logical operator in the CL search string ensures that the two records are unique; that is, there are no repeating papers.

To verify if the search string used for CC/GW/CE research may have missed a substantial portion of research papers that did not use the three searched keywords, a third search was conducted using the following search string: TOPIC: ((""greenhouse gas*" OR "GHG*") NOT ("climate" OR "climate change" OR "global warming" OR "climate emergency"))). This search yielded 28,833 articles. This represents $11.59 \%$ of articles obtained with the combined search strings. In the Discussion and Conclusions section the omission of these articles from the data analysis is explained.

The search results were at first analyzed using the Analyze Results feature of WoS. In the analysis page, it is possible to download tab-delimited text files containing a set of publication data according to the WoS category selected. Data files were obtained for the following four categories: publication years; organizations-enhanced; source titles; countries/regions. The data from these text files were then imported into Microsoft Excel for further processing and analysis. These data and analyses enabled testing Hypotheses 2 and 3. More details on the data handling procedure is provided in the Data Analysis section.

One additional procedure used was to recover keywords from the search records. This was done using the Export feature of WoS on the search results page to generate Excel files containing various attributes of each paper, including the keywords. Keywords were compiled from the top 100 cited papers from both topics (CC/GW/CE and CL), as of November $4^{\text {th }} 2020$. These keywords were used to generate word clouds using the software Wordle [5].

\section{Publication Record Highlights}

From 1910 to 1970, the publications record for CC/GW/CE shows only eight entries, with 1971 being the first year with multiple (three) records. In fact, a line can be drawn at 1970 with the publication of Berton's paper titled "Carbon dioxide and it role in climate change" [6]. This is the first of the papers on record to specifically address contemporary anthropogenic climate change. It does not mean that only in 1970 the role of humans on climate change was understood; such hypothesis dates to decades earlier. But it may be one of the first papers to consistently use the term "climate change" to describe the observed phenomena (increasing atmospheric concentration of greenhouse gases and increasing global surface temperatures, as discussed in the paper). Another evidence of this shift in terminology is that two of the three 1971 papers, those by Frisken [7] and Kopec [8], address the pressing climate challenge. This is in contrast with the first paper on this record, the 1910 Nature article by Lockyer titled "Does the Indian climate change?" [9], which discusses short term observations of changing frequency of monsoons to conclude that the climate on the sub-continent varies from year to year, with both short- and longterm trends, but the influence of humans on these trends in not addressed, in fact the opposite (the natural control of climate) is inferred. Notably, both Frisken [7] and Kopec [8] highlight that by the early 1970's it is well accepted that humans can have significant effect on the climate by air emissions, but that at that time (when $\mathrm{CO}_{2}$ atmospheric concentration have just surpassed 320 ppm [6]), the role of nature was still deemed stronger than the role of humans. 
One way to contrast the publication record of CC/GW/CE versus that of CL is to compare their most cited works. Table 1 presents the five most cited journal articles from each record, including the category data for each that later are analyzed in bulk for the full record. Briefly reviewing these ten papers (i.e. reading the paper's aims and conclusions) helps to understand if the two data records contain the required topical selection of CC/GW/CE versus CL. Eight of the ten papers are correctly classified, one is unusually misclassified, and one is an outlier, as follows.

Table 1. Five most cited journal articles from the two records (CC/GW/CE and CL).

\begin{tabular}{|c|c|c|c|c|c|}
\hline \multicolumn{6}{|c|}{ CC/GW/CE Record } \\
\hline Reference & Year & Source & Country $^{1}$ & Organization $^{1}$ & Citations $^{2}$ \\
\hline [10] & 2012 & Biogeosciences & USA & $\begin{array}{l}\text { Woods Hole } \\
\text { Res. Ctr. }\end{array}$ & 17,735 \\
\hline [11] & 2003 & $\begin{array}{l}\text { J. Geophys. } \\
\text { Res.-Atmos. }\end{array}$ & UK & Met. Off. & 5,887 \\
\hline$[12]$ & 2003 & Nature & USA & Univ. Texas & 5,833 \\
\hline [13] & 2006 & Meteorol. Z. & Austria & $\begin{array}{l}\text { Univ. Vet. } \\
\text { Med. Vienna }\end{array}$ & 4,086 \\
\hline [14] & 2004 & Nature & UK & Univ. Leeds & 4,086 \\
\hline \multicolumn{6}{|c|}{ CL Record } \\
\hline Reference & Year & Source & Country $^{1}$ & Organization $^{1}$ & Citations $^{2}$ \\
\hline [15] & 1996 & $\begin{array}{l}\text { Bull. Amer. } \\
\text { Meteorol. Soc. }\end{array}$ & USA & $\begin{array}{l}\text { NATL CTR } \\
\text { ENVIRONM } \\
\text { PREDICT }\end{array}$ & 20,347 \\
\hline [16] & 2005 & $\begin{array}{l}\text { Int. J. Clima- } \\
\text { tol. }\end{array}$ & USA & $\begin{array}{l}\text { Univ Calif } \\
\text { Berkeley }\end{array}$ & 12,060 \\
\hline [17] & 2012 & $\begin{array}{l}\text { Bull. Amer. } \\
\text { Meteorol. Soc. }\end{array}$ & USA & $\begin{array}{c}\text { Lawrence Liv- } \\
\text { ermore Natl } \\
\text { Lab }\end{array}$ & 7,521 \\
\hline [18] & 2006 & Ecol. Model. & USA & $\begin{array}{c}\text { AT\&T Labs } \\
\text { Res }\end{array}$ & 7,426 \\
\hline [19] & 2000 & Science & USA & Stanford Univ & 6,846 \\
\hline
\end{tabular}

${ }^{1}$ Of corresponding author.

${ }^{2}$ WoS Core citations as of November $4^{\text {th }} 2020$.

Berner et al. [10] looked at the increasing risk of forest fires in boreal areas of Russia due to higher temperatures and drier air. They also concluded that fires diminish $\mathrm{CO}_{2}$ sequestration into the boreal sinks. Rayner et al. [11] present sea ice and sea surface temperature and nighttime marine air temperature data sets, starting from 1871. That is, the study covers parameters pertinent for climate change research, and the contemporary post-industrial revolution period attributed to anthropogenic climate change. Parmesan and Yohe [12] showed that climate change effects on living systems can be discerned from non-climatic effects by looking for systematic trends over diverse species and geographic regions. Kottek et al. [13] provide a climate classification map update valid for the second half of the $20^{\text {th }}$ century, which was updated from the original 1961 Wladimir Köppen map. One motivation for this update was that climate changes have occurred and thus up-todate global temperature and precipitation data sets were required to update the geographical distribution of the various climate zones (equatorial, arid, warm temperate, snow, and polar, and the various sub-classifications). Thomas et al. [14] showed how climate change leads to species-level extinction. They concluded that $18 \%$ to $35 \%$ of species will be committed to extinction by 2050 because of climate change, in part because of habit loss due to changes in biome. All of these five highly cited papers are thus correctly classified under the CC/GW/CE topic. 
Kalnay et al. [15] investigated how improvements to climate monitoring can avoid misinterpretation of climate variations that are not a result of climate change. The study is not concerned about studying climate change directly, even if the advances can benefit climate change research. Hijmans et al. [16] developed a method for very high resolution interpolation of temperature and precipitation climate data, which can be used to generate accurate climate surfaces (i.e. continuous grids). This advance can help improve analysis of climate change, since more accurate values are obtained, though this was not the main aim of the study. An example was provided on how for Madagascar, the newly interpolated data set does not how direct evidence of climate change between 1930 and 1990. Another example stated that insufficiently dense station network can lead to erroneous climate change conclusions. Phillips et al. [18] present a model of the distribution of biological species due to geographic distribution, including climatic variables and conditions. The model was posed as being able to predict movement of species due to climate change, such as invasive species, but this was not the study's main aim. These are the three out of five highly cited papers correctly classified under CL.

Tenenbaum et al. [19] is the outlier. This paper does have relevance for CL research, as it pertains to development of nonlinear algorithms to find trends in complex and large data sets, such as climate data sets, and is certainly not about CC/GW/CE. So while correctly classified, due to the use of the word "climate" in the abstract, the paper's topic is largely mathematical rather than about natural or engineering sciences. Taylor et al. [17] is the paper that was unusually misclassified. This article does not have an abstract registered in WoS, and the article's single keyword registered in WoS is "climate" (the article itself does not have a keywords list). The article is in fact about CC/GW/CE research, thus the unusually incomplete record for this article caused it to be misclassified. These two papers highlight that the CL record is less robust than the CC/GW/CE record, particularly because of the CL record's less specific search string. While a weakness, the more analytical data processing presented in the Data Analysis section will show that this record is still useful for contrasting against the CC/GW/CE to yield data-set level (as opposed to paper-by-paper) trends and conclusions.

Figures 1 and 2 present the word clouds generated for the keywords extracted from the top 100 most cited papers in each record. In contrast to the aforementioned analysis of the top 5 most cited papers in each record, which showed significant differences in the two records, the word clouds are qualitatively less precise. It is understandable that research on CC/GW/CE will use many similar keywords to more general research on the Earth's climate, thus several terms are similarly enlarged on both clouds. For example, model, variability, temperature, precipitation and circulation some of the main words on both clouds. In fact, the vast majority of words from Figure 2 also appear in Figure 1, even if in different size. Climate-change and $\mathrm{CO}_{2}$ are the two terms in Figure 1 that are particularly distinct from Figure 2, which is expected given that these are key topics of $\mathrm{CC} / \mathrm{GW} / \mathrm{CE}$ research. The conclusion from word clouds is that they are visually interesting, but are not ideal tools to evaluate two unique but topically similar publication records. As aforementioned, the Data Analysis section presents more deeply analytical comparisons between the two records, from which clearer trends can be seen. 


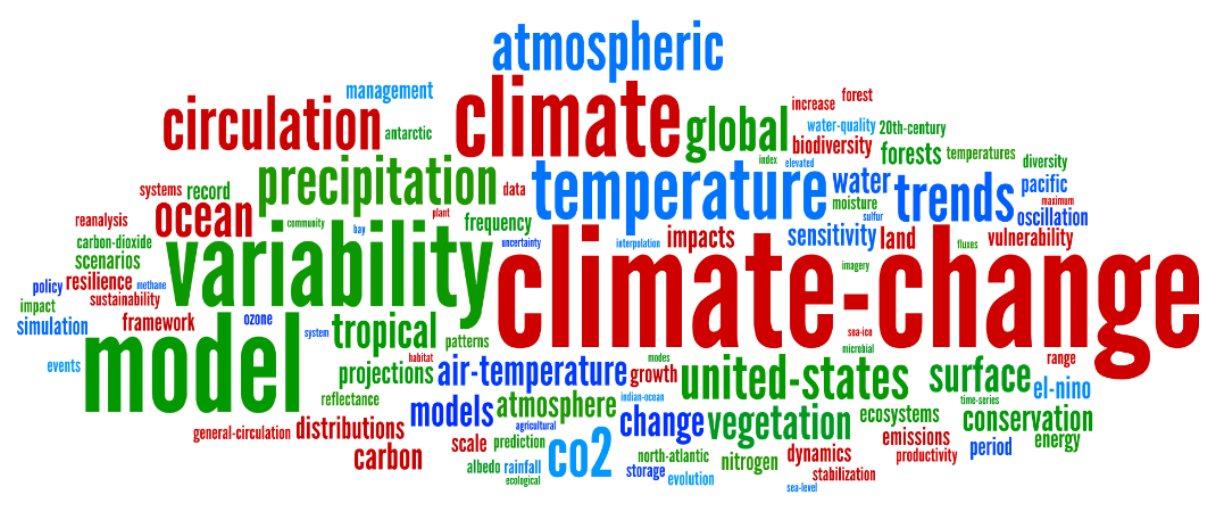

Figure 1. Word cloud of keywords from top 100 most cited papers on CC/GW/CE research.

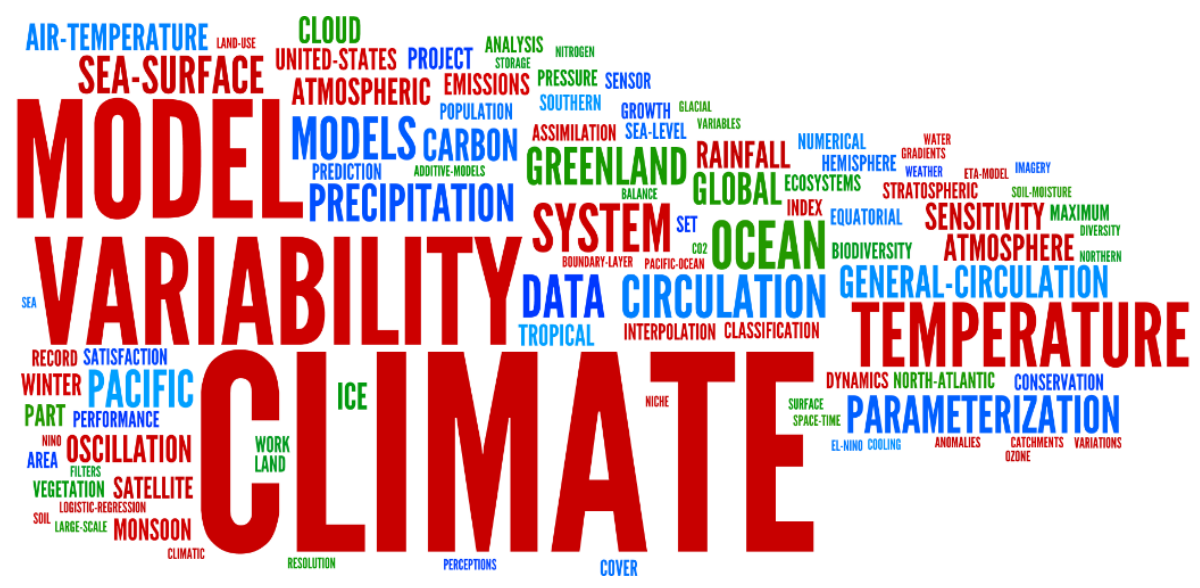

Figure 2. Word cloud of keywords from top 100 most cited papers on CL research.

\section{Data Analysis}

This section is sub-divided into the four categories of data collection and analysis of the publication records: (i) year of publication; (ii) country (corresponding author's) of publication; (iii) source (i.e. journal) of publication; and (iv) organization (corresponding author's) of publication.

\subsection{Year of Publication}

Figure 3 presents the data analysis for year of publication, ranging from 1910 to 2020. The number of articles published per year in the two publication records (CC/GW/CE and $\mathrm{CL}$ ) were compiled from WoS. For each year, a ratio of the number of articles in the $\mathrm{CC} / \mathrm{GW} / \mathrm{CE}$ record over the number of articles in the CL record was calculated. This ratio is plotted as a function of time on Figure 3a. The purpose of this ratio is to help visualize when the scientific record became more enriched in CC/GW/CE versus general CL research; that is, when the ratio surpasses a value of 1 . This occurred in 2011, and the ratio has since increased to 1.260 in 2019 (full year record) and then to 1.346 in 2020 (record up to October $20^{\text {th }}$ ). Notably, before 1989 , the ratio was consistently smaller than 0.1 , meaning that CC/GW/CE research was scarce for much of the $20^{\text {th }}$ century. The exceptions in 1910, 1939 and 1941 are due to the very small number of CL publications on record for those decades. From 1989 onwards, the ratio increases nearly every year (in fact, it increases 26 out of 31 times, and every year since 2001). 

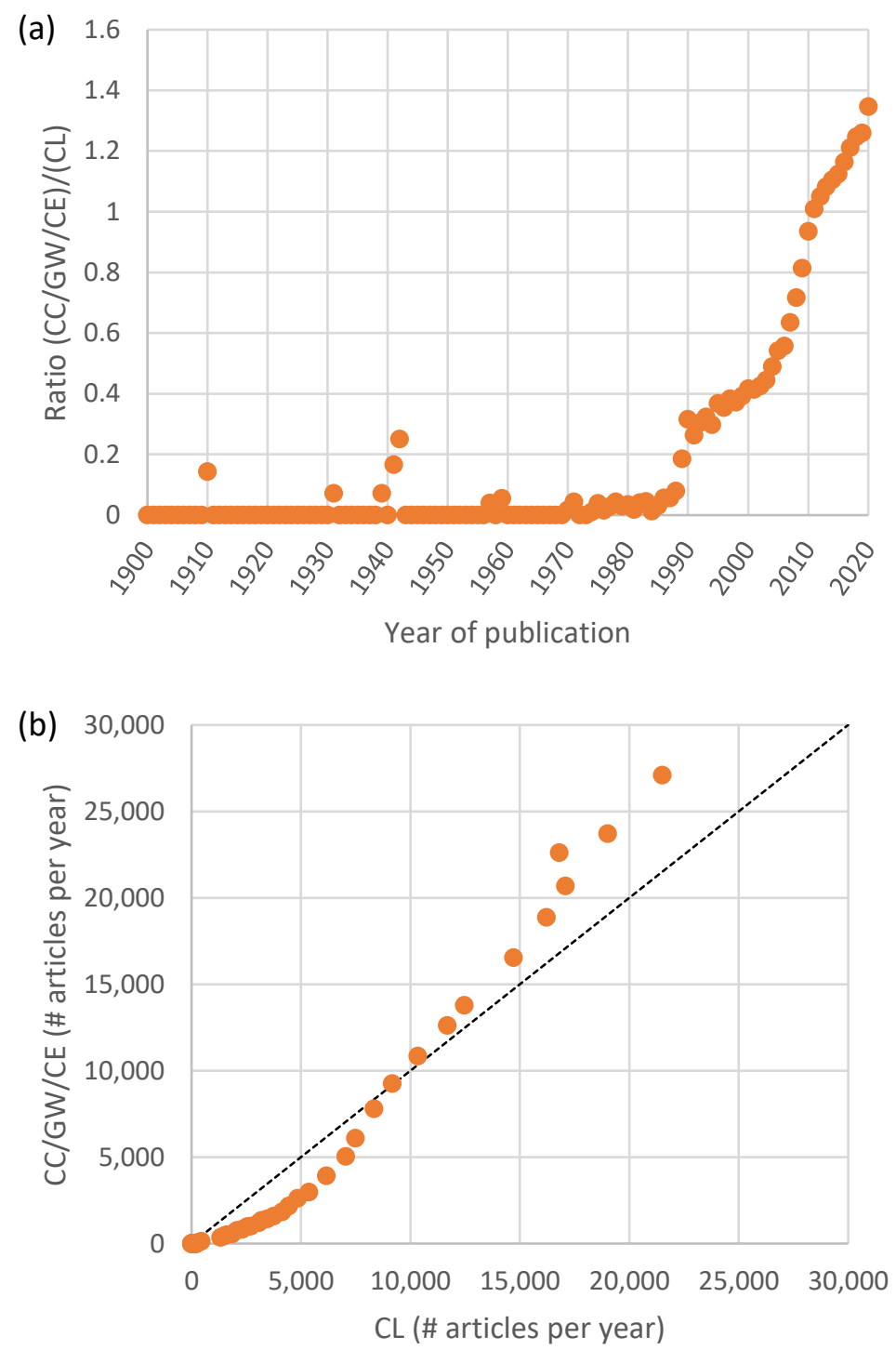

Figure 3. Data for CC/GW/CE and CL records for year of publication: (a) Publication ratio $((\mathrm{CC} / \mathrm{GW} / \mathrm{CE}) /(\mathrm{CL}))$ as a function of time (years); (b) Number of publications per year in the $\mathrm{CC} / \mathrm{GW} / \mathrm{CE}$ record versus those in the $\mathrm{CL}$ record (dashed line illustrates the 1:1 mark).

The number of publications in both records rose by orders of magnitude over the last several decades, and Figure $3 \mathrm{~b}$ helps to visualize this climb. The CL record crossed 100 publications in a year in 1975, versus 1990 for the CC/GW/CE record. The CL record also crossed 1,000 publications is a year first, in 1991, followed by the CC/GW/CE record in 1998. Then both records breached 10,000 articles in a year in 2012. This coincides almost exactly with the 2011 threshold, when the CC/GW/CE record overtook the CL in number of publications per year. Points on Figure $3 b$ above the dashed line indicate the records from the last decade, while those below the dashed line correspond to the pre-2011 record.

\subsection{Country/Region of Publication}

Figure 4 presents the data analysis for country (or region) of publication, for the full records ranging from 1910 to 2020. The number of articles published per country/region in the two publication records (CC/GW/CE and CL), from 1910 to 2020, were compiled from WoS. For each country/region, a ratio of the number of articles in the CC/GW/CE record over the number of articles in the CL record was calculated. This ratio is plotted for each country/region on Figure 3a, ordered from largest to smallest ratio. Countries/regions with a ratio greater than one have been more engaged in CC/GW/CE research, while 
those with ratio smaller than 1 have been more engaged in CL research. The number of countries and regions for which a ratio was calculated in 215. An additional 32 countries of regions did not have a ratio calculated, either due to no CC/GW/CE or CL articles on record (this occurs for small states such as Equatorial Guinea and Turks and Caicos, among others, or for states that no longer exist such as the German Democratic Republic and Rhodesia). Figure 3 a shows that slightly more than half of countries/regions have a ratio greater than 1 , showing that the climate challenge has become the dominant scientific topic in many places around the world. It is notable that the majority of countries/regions with ratio greater than 2 are island states, such as Tuvalu and Cook Islands (ratio $=3.00$ ), Marshall Islands and Palau (ratio = 5.50), and Kiribati and Falkland Islands (ratio = 11.00). This highlights that small island states are at most risk of the catastrophic effects of climate change, particularly rising sea levels [20-24]. In contrast, countries and regions with ratio lower than 0.50 tend to be those of lower gross domestic product, those in arid regions of the world, or those landlocked nations, such as Albania, Djibouti, Algeria and Turkmenistan. Other countries of interest to view ratios for are those with long publication history (USA (0.90), England (1.16), France (0.85), Germany (0.91)) and the emerging/fast growing economies (China (1.05), India (0.99), Brazil (0.75), South Africa (1.24)). The average ratio of these eight countries is very close to $1(0.98)$, showing that such countries contribute with diverse research. On a case-by-case basis it may be possible to claim which countries are more engaged in the climate challenge, but this has to also take into account the fact that rich amount of older literature from some countries, when CL research was dominant, may be holding back their ratio, but that it does not mean that currently these countries are just as engaged as others in CC/GW/CE research. 

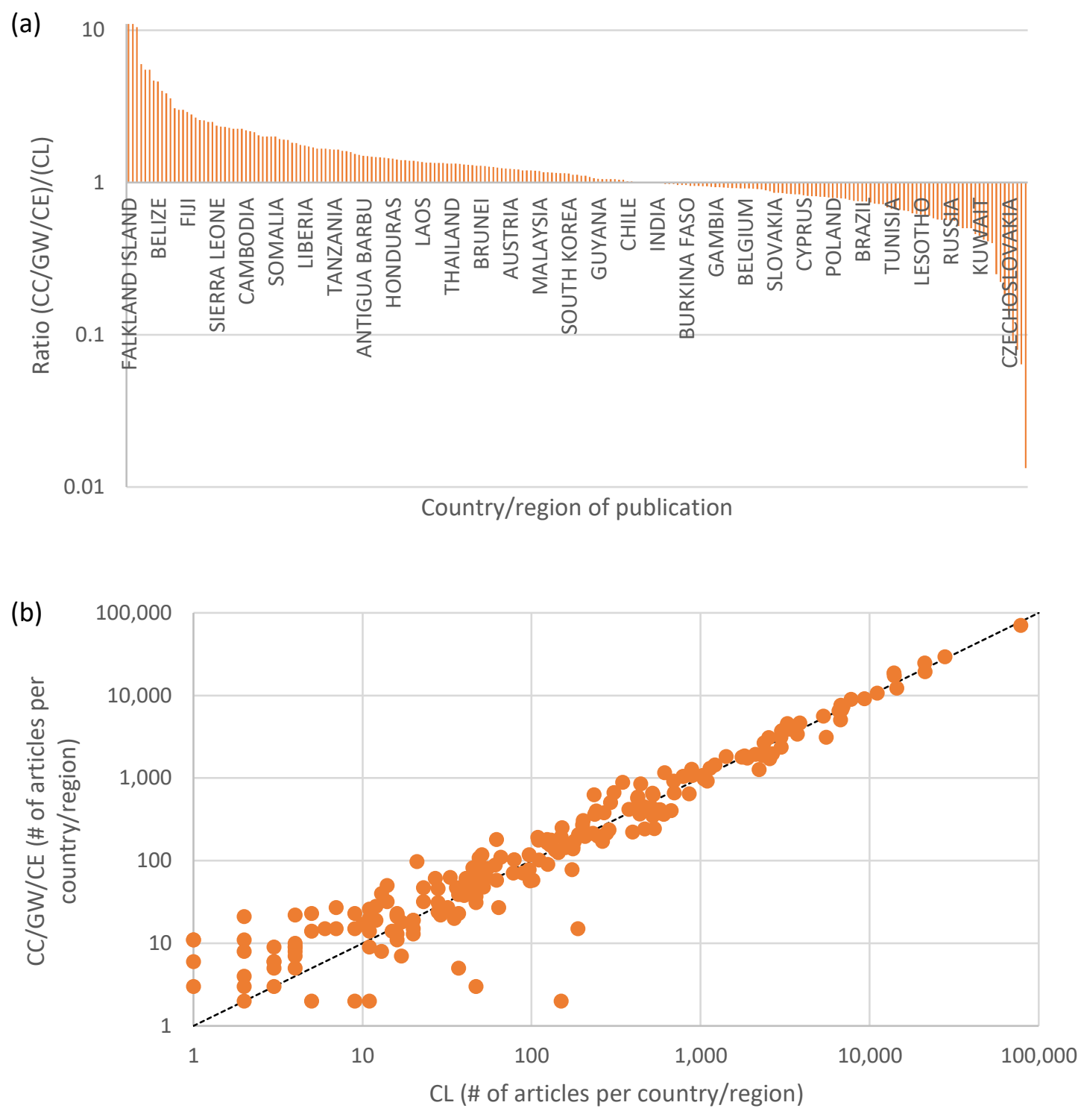

Figure 4. Data for CC/GW/CE and CL records for country/region of publication: (a) Publication ratio $((\mathrm{CC} / \mathrm{GW} / \mathrm{CE}) /(\mathrm{CL}))$ for 215 countries/regions, ordered from highest to lowest ratio (axis labels are provided for a selection of states); (b) Number of publications per country/region in the $\mathrm{CC} / \mathrm{GW} / \mathrm{CE}$ record versus those in the CL record (dashed line illustrates the 1:1 mark).

Figure $4 \mathrm{~b}$ provides a different view of the country/region publication records. By plotting the number of CC/GW/CE publications for each country/region versus the number of CL publications in the same country/region, it is possible to see a focusing effect about the 1:1 dashed line. Countries that have published more, have more diverse body of literature, and tend towards the 1:1 line (the USA is the highest point). Countries that have published less are more likely to be more engaged in recent research, and thus have more CC/GW/CE articles than CL articles. Notable outliers with more than 10 CL publications (i.e. farthest from the 1:1 line and with robust body of literature) are Fiji (2.90 ratio) and Monaco (4.67 ratio), both above the line. The outliers below the line are no longer existing states such as the USSR, Czechoslovakia, and the Federal Republic of Germany, which explains their low number of CC/GW/CE publications. 


\subsection{Source of Publication}

Table 2 and Figure 5 present the data analysis for source (i.e. journals indexed in WoS) of publication, for a part of the records, ranging from 1910 to 2020 . The sources analyzed are the top 20 venues of publications from each record in terms of number of publications in each source. The top 20 were chosen to make the analysis manageable from a reporting and graphing perspective. The top 20 of the CC/GW/CE record represents $18.49 \%$ of all articles in this record, and the top 20 of the CL record represents a very similar $18.78 \%$ of that record. It is deemed that observations and trends made from the top 20 will be valid as a proxy for the trends of the full record.

Table 2. Top 20 sources of articles from the two records (CC/GW/CE and CL). Number of articles in each source, and percentage of total number of articles in the full record. Bolded entries are the top 20 of each record.

\begin{tabular}{|c|c|c|c|c|c|}
\hline CC/GW/CE Sources & Articles & \% of 219,830 & CL Sources & Articles & \% of 231,016 \\
\hline ATMOSPHERIC CHEMISTRY AND PHYSICS & 709 & 0.003 & ATMOSPHERIC CHEMISTRY AND PHYSICS & 2359 & 1.021 \\
\hline BUILDING AND ENVIRONMENT & 239 & 0.001 & BUILDING AND ENVIRONMENT & 1036 & 0.448 \\
\hline CLIMATE DYNAMICS & 1698 & 0.772 & CLIMATE DYNAMICS & 3268 & 1.415 \\
\hline CLIMATIC CHANGE & 3188 & 1.450 & CLIMATIC CHANGE & 915 & 0.004 \\
\hline EARTH AND PLANETARY SCIENCE LETTERS & 547 & 0.002 & EARTH AND PLANETARY SCIENCE LETTERS & 1169 & 0.506 \\
\hline ENERGY AND BUILDINGS & 319 & 0.001 & ENERGY AND BUILDINGS & 1590 & 0.688 \\
\hline ENERGY POLICY & 1510 & 0.687 & ENERGY POLICY & 623 & 0.003 \\
\hline ENVIRONMENTAL RESEARCH LETTERS & 1769 & 0.805 & ENVIRONMENTAL RESEARCH LETTERS & 811 & 0.004 \\
\hline FOREST ECOLOGY AND MANAGEMENT & 1317 & 0.599 & FOREST ECOLOGY AND MANAGEMENT & 938 & 0.004 \\
\hline GEOPHYSICAL RESEARCH LETTERS & 2585 & 1.176 & GEOPHYSICAL RESEARCH LETTERS & 4842 & 2.096 \\
\hline GLOBAL CHANGE BIOLOGY & 3266 & 1.486 & GLOBAL CHANGE BIOLOGY & 634 & 0.003 \\
\hline INTERNATIONAL JOURNAL OF CLIMATOLOGY & 1636 & 0.744 & INTERNATIONAL JOURNAL OF CLIMATOLOGY & 2329 & 1.008 \\
\hline JOURNAL OF CLEANER PRODUCTION & 2204 & 1.003 & JOURNAL OF CLEANER PRODUCTION & 474 & 0.002 \\
\hline JOURNAL OF CLIMATE & 2019 & 0.918 & JOURNAL OF CLIMATE & 5279 & 2.285 \\
\hline JOURNAL OF GEOPHYSICAL RESEARCH ATMOSPHERES & 1668 & 0.759 & JOURNAL OF GEOPHYSICAL RESEARCH ATMOSPHERES & 5234 & 2.266 \\
\hline JOURNAL OF GEOPHYSICAL RESEARCH OCEANS & 420 & 0.002 & JOURNAL OF GEOPHYSICAL RESEARCH OCEANS & 1149 & 0.497 \\
\hline JOURNAL OF HYDROLOGY & 1637 & 0.745 & JOURNAL OF HYDROLOGY & 1395 & 0.604 \\
\hline JOURNAL OF THE ATMOSPHERIC SCIENCES & 146 & 0.001 & JOURNAL OF THE ATMOSPHERIC SCIENCES & 1093 & 0.473 \\
\hline PALAEOGEOGRAPHY PALAEOCLIMATOLOGY PALAEOECOL- & & & PALAEOGEOGRAPHY PALAEOCLIMATOLOGY PALAEOECOL- & & \\
\hline OGY & 1017 & 0.005 & OGY & 2220 & 0.961 \\
\hline PLOS ONE & 3375 & 1.535 & PLOS ONE & 1679 & 0.727 \\
\hline PROCEEDINGS OF THE NATIONAL ACADEMY OF SCIENCES & & & PROCEEDINGS OF THE NATIONAL ACADEMY OF SCIENCES OF & & \\
\hline OF THE UNITED STATES OF AMERICA & 1510 & 0.687 & THE UNITED STATES OF AMERICA & 862 & 0.004 \\
\hline QUATERNARY SCIENCE REVIEWS & 1167 & 0.531 & QUATERNARY INTERNATIONAL & 1692 & 0.732 \\
\hline QUATERNARY SCIENCE REVIEWS & 1167 & 0.005 & QUATERNARY SCIENCE REVIEWS & 1761 & 0.762 \\
\hline REMOTE SENSING & 1051 & 0.005 & REMOTE SENSING & 1117 & 0.484 \\
\hline SCIENCE OF THE TOTAL ENVIRONMENT & 3101 & 1.411 & SCIENCE OF THE TOTAL ENVIRONMENT & 1419 & 0.614 \\
\hline SCIENTIFIC REPORTS & 1982 & 0.902 & SCIENTIFIC REPORTS & 1326 & 0.574 \\
\hline SUSTAINABILITY & 2309 & 1.050 & SUSTAINABILITY & 845 & 0.004 \\
\hline THEORETICAL AND APPLIED CLIMATOLOGY & 1113 & 0.506 & THEORETICAL AND APPLIED CLIMATOLOGY & 1428 & 0.618 \\
\hline WATER & 1598 & 0.727 & WATER & 650 & 0.003 \\
\hline
\end{tabular}




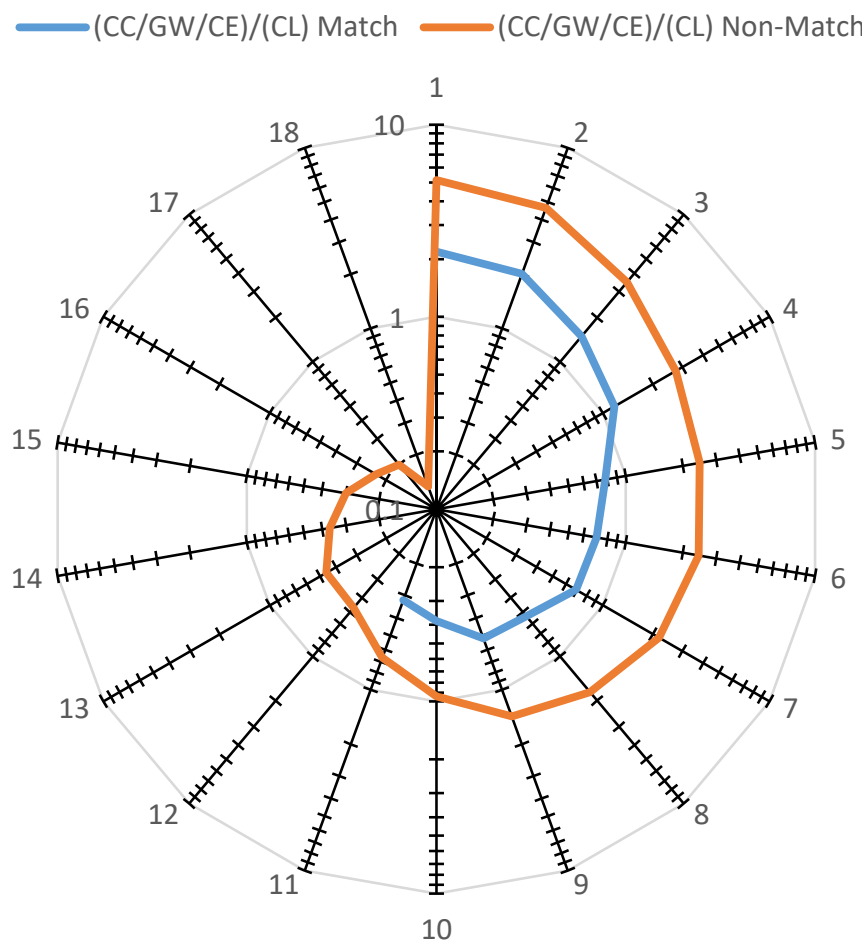

Figure 5. Publication ratio ((CC/GW/CE)/(CL)) for 29 journals, categorized as 'match' or 'nonmatch' based on appearance or not in both top 20 lists, ordered from highest to lowest ratio (one curve contains 18 entries and the other 11).

Table 2 presents the number of articles from each record that appear in these journals. A total of 29 journals appear in Table 2, organized in alphabetic order, since there is partial overlap of the top 20 from each record; in fact, there 11 journals that are common to both top 20 's (these are referred to as 'match' journals), and 9 journals in each top 20 that is not in the other top 20 (these are referred to as 'non-match' journals). The top journal in the CC/GW/CE record is PLOS One, with 3375 articles representing 1.535\% of the full record. The top journal in the CL record is the Journal of Climate, with 5279 articles representing $2.285 \%$ of the full record. Both of these journals are in both top 20 lists, with PLOS One having a stronger record of CC/GW/CE articles as given by a ratio (as previously calculated to compare records) of 2.01, while the Journal of Climate has a stronger record of general CL research, with a 0.38 ratio. The 'match' journal with the highest ratio (2.19) is Science of the Total Environment, while the Journal of Geophysical Research Atmospheres has the lowest ratio of 0.32 . The range of ratios is larger for 'non-match' journals. Here the highest ratio is 5.15 for Global Change Biology, and the smallest ratio is 0.13 for Journal of the Atmospheric Sciences. These ratios agree with the perception that can be taken about each of these journals. Journals like PLOS One, Science of the Total Environment and Global Change Biology appeal to more applied areas of research, including the applied sciences and engineering, and have wider aims and scopes, while journals such as the Journal of Climate, Journal of Geophysical Research Atmosphere and Journal of the Atmospheric Sciences appeal to more fundamental and specialized research.

Figure 5 helps to highlight the different scopes of the 29 journals listed in Table 2. Here, the ratios for each journal are plotted and categorized according to 'match' or 'nonmatch' journals. The spider plot shows data arranged from largest to smallest ratio for each category (i.e. each line). Had there been no significant difference in the distribution of the articles across the various journals, both of these lines would be very close to the value of 1 . It is clear that the 'non-match' line deviates the most from 1 , with nearly every value much higher or much lower than 1 . Even the 'match' line deviates significantly from 
1. The ratio value closest to 1 from both categories is that of the journal Remote Sensing (0.94). This is not surprising as remote sensing is a climate monitoring technique that can be used both for general climate research as well as to track changes in the climate due to anthropogenic effects [25-27]. What can be concluded from this analysis is that journals and authors are able to distinguish the research topics sufficiently to steer more $\mathrm{CC} / \mathrm{GW} / \mathrm{CE}$ research to certain journals and more general CL research to other journals. This helps to confirm that these two topics are distinct in practice.

\subsection{Organization of Publication}

Table 3 and Figure 6 present the data analysis for organization (i.e. universities, research institutes, and other research-intensive organizations, associated with the corresponding author's primary affiliation) of publication, for a part of the records, ranging from 1910 to 2020. As with sources, the organizations analyzed are the top 20 from each record, and identical data analysis procedure was used here. The top 20 of the CC/GW/CE record represents $36.92 \%$ of all articles in this record, and the top 20 of the CL record represents a slightly higher $39.07 \%$ of that record. A total of 26 organizations appear in Table 3 , signifying that there are 14 common organizations within the top 20 (i.e. 'match' organizations), and 6 'non-match' organizations. Here, the top three organizations are the same on both records, with the Chinese Academy of Sciences (China) being slightly more engaged in CC/GW/CE research, and the University of California System (USA) and the Centre National de la Recherche Scientifique (France) being slightly more productive in general CL research; though their ratios are very close to $1(1.03,0.98$ and 0.81 , respectively). In fact, the ratios of these organizations are much closer to 1 , on average, than those of the journals. The highest ratio among the 26 organizations is 1.74 for the United States Forest Service, and the lowest ratio is 0.40 for two NASA organizations (the main NASA organization, and the Goddard Space Flight Centre). This suggests that academic organizations may have more varied research, and hence ratios closer to 1, while governmental organizations may be more focused on a particular line of research, and thus rations more different than 1 . Though such conclusion would require analysis of a large set of organizations, and is complicated by some countries have organizations that have a dual academic and institutional role. 
Table 3. Top 20 organizations of articles from the two records (CC/GW/CE and CL). Number of articles from each organization, and percentage of total number of articles in the full record. Bolded entries are the top 20 of each record.

\begin{tabular}{|c|c|c|c|c|c|}
\hline CC/GW/CE Organizations & Articles & \% of 219,830 & $\underline{\text { CL Organizations }}$ & Articles & \% of 231,016 \\
\hline CENTRE NATIONAL DE LA RECHERCHE SCIENTIFIQUE CNRS & 7079 & 3.220 & CENTRE NATIONAL DE LA RECHERCHE SCIENTIFIQUE CNRS & 8770 & 3.796 \\
\hline CHINESE ACADEMY OF SCIENCES & 12132 & 5.519 & CHINESE ACADEMY OF SCIENCES & 11770 & 5.095 \\
\hline COLUMBIA UNIVERSITY & 2132 & 0.970 & COLUMBIA UNIVERSITY & 3011 & 1.303 \\
\hline COMMONWEALTH SCIENTIFIC INDUSTRIAL RESEARCH ORGANISA- & & & COMMONWEALTH SCIENTIFIC INDUSTRIAL RESEARCH OR- & & \\
\hline \multirow[t]{2}{*}{ TION CSIRO } & 3195 & 1.453 & GANISATION CSIRO & 2499 & 1.082 \\
\hline & & & CONSEJO SUPERIOR DE INVESTIGACIONES CIENTIFICAS & & \\
\hline CONSEJO SUPERIOR DE INVESTIGACIONES CIENTIFICAS CSIC & 3028 & 1.377 & CSIC & 2862 & 1.239 \\
\hline HELMHOLTZ ASSOCIATION & 4221 & 1.920 & HELMHOLTZ ASSOCIATION & 5382 & 2.330 \\
\hline INRAE & 2600 & 1.183 & INRAE & 1972 & 0.854 \\
\hline INSTITUT DE RECHERCHE POUR LE DEVELOPPEMENT IRD & 2770 & 1.260 & INSTITUT DE RECHERCHE POUR LE DEVELOPPEMENT IRD & 3021 & 1.308 \\
\hline MAX PLANCK SOCIETY & 1814 & 0.825 & MAX PLANCK SOCIETY & 2731 & 1.182 \\
\hline NASA GODDARD SPACE FLIGHT CENTER & 1282 & 0.583 & NASA GODDARD SPACE FLIGHT CENTER & 3173 & 1.373 \\
\hline NATIONAL AERONAUTICS SPACE ADMINISTRATION NASA & 2286 & 1.040 & NATIONAL AERONAUTICS SPACE ADMINISTRATION NASA & 5674 & 2.456 \\
\hline NATIONAL CENTER ATMOSPHERIC RESEARCH NCAR USA & 1816 & 0.826 & NATIONAL CENTER ATMOSPHERIC RESEARCH NCAR USA & 3626 & 1.570 \\
\hline NATIONAL OCEANIC ATMOSPHERIC ADMIN NOAA USA & 3358 & 1.528 & NATIONAL OCEANIC ATMOSPHERIC ADMIN NOAA USA & 5373 & 2.326 \\
\hline RUSSIAN ACADEMY OF SCIENCES & 1910 & 0.869 & RUSSIAN ACADEMY OF SCIENCES & 3676 & 1.591 \\
\hline STATE UNIVERSITY SYSTEM OF FLORIDA & 3154 & 1.435 & STATE UNIVERSITY SYSTEM OF FLORIDA & 2892 & 1.252 \\
\hline UNITED STATES DEPARTMENT OF AGRICULTURE USDA & 4149 & 1.887 & UNITED STATES DEPARTMENT OF AGRICULTURE USDA & 3013 & 1.304 \\
\hline UNITED STATES DEPARTMENT OF ENERGY DOE & 3130 & 1.424 & UNITED STATES DEPARTMENT OF ENERGY DOE & 3522 & 1.525 \\
\hline UNITED STATES DEPARTMENT OF THE INTERIOR & 3951 & 1.797 & UNITED STATES DEPARTMENT OF THE INTERIOR & 2764 & 1.196 \\
\hline UNITED STATES FOREST SERVICE & 2389 & 1.087 & UNITED STATES FOREST SERVICE & 1371 & 0.593 \\
\hline UNITED STATES GEOLOGICAL SURVEY & 3413 & 1.553 & UNITED STATES GEOLOGICAL SURVEY & 2532 & 1.096 \\
\hline UNIVERSITY OF CALIFORNIA SYSTEM & 8654 & 3.937 & UNIVERSITY OF CALIFORNIA SYSTEM & 8838 & 3.826 \\
\hline UNIVERSITY OF CHINESE ACADEMY OF SCIENCES CAS & 4108 & 1.869 & UNIVERSITY OF CHINESE ACADEMY OF SCIENCES CAS & 3309 & 1.432 \\
\hline UNIVERSITY OF COLORADO BOULDER & 2179 & 0.991 & UNIVERSITY OF COLORADO BOULDER & 3337 & 1.444 \\
\hline UNIVERSITY OF COLORADO SYSTEM & 2335 & 1.062 & UNIVERSITY OF COLORADO SYSTEM & 3507 & 1.518 \\
\hline UNIVERSITY OF LONDON & 2766 & 1.258 & UNIVERSITY OF LONDON & 2358 & 1.021 \\
\hline WAGENINGEN UNIVERSITY RESEARCH & 2450 & 1.114 & WAGENINGEN UNIVERSITY RESEARCH & 1467 & 0.635 \\
\hline
\end{tabular}

Figure 6, in contrast to Figure 5, makes it clear that organizational information is not enough to place a research as belonging to one record or another. Both the 'match' and 'non-match' lines deviated by small extents away from the ratio of 1 level, with the 'nonmatch' line deviating more, as would be expected. For comparison with the earlier case, the ratio value closest to 1 from both categories is that of the University of California System (0.98). Notable about this organization is that it consists of nine campuses offering comprehensive education, with varying levels of research excellence (e.g. excellent (Berkeley), very good (Davis), less highly ranked (Riverside), emerging (Merced) [28]). This can explain the diversity of research output, covering both CC/GW/CE and CL topics. Of course, this diversity of topic is an average since 1900, and it is possible that in recent years the research in many organizations has shifted towards the climate challenge, as the year and country trends presented earlier suggested. 


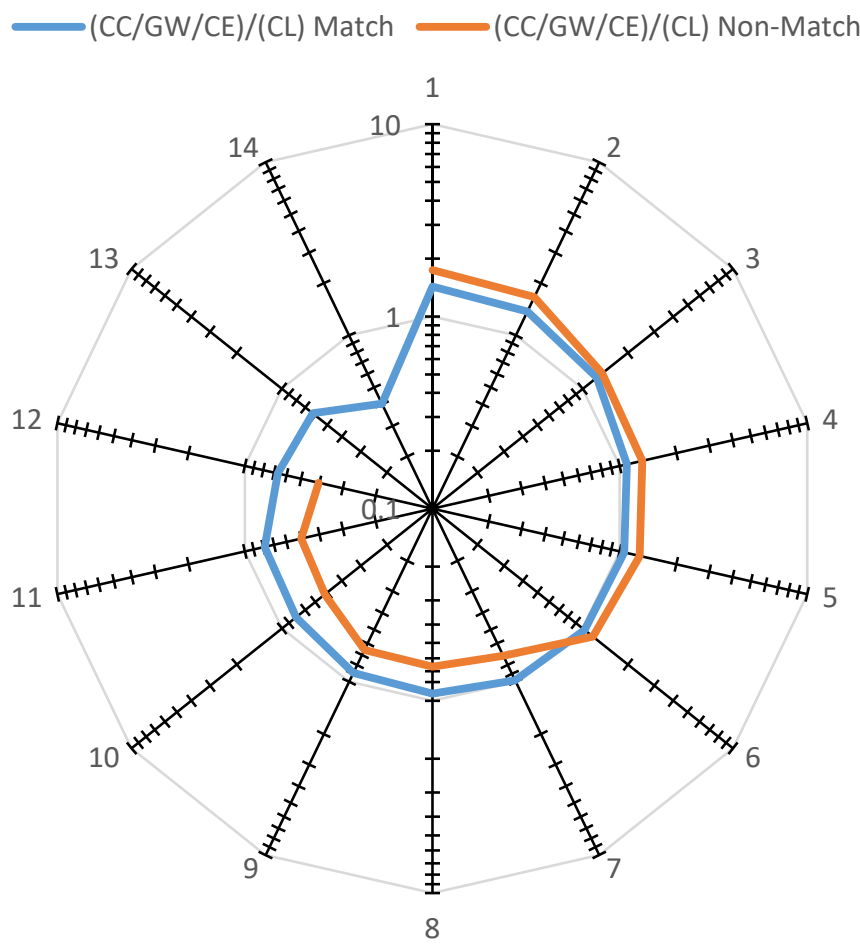

Figure 6. Publication ratio ((CC/GW/CE)/(CL)) for 26 organizations, categorized as 'match' or 'non-match' based on appearance or not in both top 20 lists, ordered from highest to lowest ratio (one curve contains 14 entries and the other 12).

\section{Discussion and Conclusions}

Here we can re-visit the three hypotheses and reach conclusions about their claims. With regards to hypothesis 1 , it was possible to distinguish the scientist literature linked to CC/GW/CE research from that pertaining to CL research using the two search strings tested. This was verified by reviewing the scope of a number of highly cited papers in both records, and is further supported by the trends seen with regards to years of publication, country/region of publication, and source of publication. That is, in these three categories, the publication records showed significant numerical and graphical differences, and these could at times be explained rationally, with basis on data interpretation. Evidence was found that the two publication records contained some misinterpreted publications and outliers, but it is deemed that the consistency of trends observed signify that these issues are minor and acceptable given the simplicity of the publication record assemblage method. A third search string, related to the topic of greenhouse gases, was also tested, but its data did not become part of this study's analysis. The reason for this is that such search string finds many articles that discuss the emissions of greenhouse gases (e.g. from flue gas stacks [29] or from livestock farming [30]) and technologies to control or mitigate these emissions (e.g. via carbon sequestration [31] or green energy [32]). As such, these articles fall outside the scope of the two topical records of interest here. This is further evidence that the two search strings used are effective in reaching their intended goal.

With hypothesis 1 confirmed, it is also possible to confirm hypothesis 2 . The publication year data clearly shows that the scientific literature has become enriched in $\mathrm{CC} / \mathrm{GW} / \mathrm{CE}$ works in relation to CL works. This is despite both of these records experiencing massive growth over the decades (from under 100 articles per year in the first half of the $20^{\text {th }}$ century to over 10,000 articles per year in recent years). It is clear that the more pressing the climate challenge becomes, and its effects actually witnessed [33], the more research is being undertaken to forecast the avoidable or unavoidable impacts [34,35]. It is difficult to foresee for how much longer the publication ratio devised in this study will 
continue to rise, globally or country-by-country, as climate research will become increasingly important in the framework of a sustainable society, so it will be worth revisiting this in a decade or more. Perhaps by then another keyword could be added to complement CC/GW/CE. As of December 27th 2020, 84.85\% of this record is retrieved using only CC and excluding (via the NOR operator) the other two search terms; this compares to only $9.20 \%$ of the record that only contains GW, and a mere $0.019 \%$ of the record that only contains CE. A simple search for CE yields 99 articles, 86 of which published since 2019, and the oldest from 2011 [36] being the most cited to date. This shows that this popular term (in the greater public sphere) is not yet commonly used scientifically; will it eventually be?

Hypothesis 3 was partly confirmed. The data and its interpretation show that the two publications records have distinct differences in terms of size (i.e. number of publications) when it comes to the originating country/region and venue (journal) of publication. Yet the two records are nearly indistinguishable when the criteria used is the organization responsible for producing the work. As was explained, research organizations have broad research interests, and it is understandable that the same departments and research groups that perform CC/GW/CE research also tend to perform CL research. Of course, this would not be the case at the researcher level, since expertise for these two topics of research is sufficiently different. WoS allows data analysis at the researcher (i.e. corresponding author level). However, in addition to the number of entries being very large (there are over 100,000 corresponding authors listed in the most recent CC/GW/CE and CL records), there is ambiguity with common author names (i.e. same last name and same first letter of first name), making any possible analysis less accurate. Such analysis would thus require close scrutiny at the article level.

Supplementary Materials: The following are available online at www.mdpi.com/xxx/s1, Years CCGW-CE.txt: raw data file with publications per year data, Years CL.txt: raw data file with publications per year data, Countries CC-GW-CE.txt: raw data file with publications per country/region data, Countries CL.txt: raw data file with publications per country/region data, Sources CC-GWCE.txt: raw data file with publications per source data, Sources CL.txt: raw data file with publications per source data, Organizations CC-GW-CE.txt: raw data file with publications per organization data, Organizations CL.txt: raw data file with publications per organization data, top100_CCGWCE.xls: raw data file with publication data for top 100 papers, top100_CL.xls: raw data file with publication data for top 100 papers.

Funding: This research received no external funding.

Institutional Review Board Statement: Not applicable.

Informed Consent Statement: Not applicable.

Data Availability Statement: The data presented in this study are available in DataFile.zip.

Acknowledgments: The author acknowledges the University of Guelph Library for the Web of Science access provided, which made this study possible.

Conflicts of Interest: The author declares no conflict of interest.

\section{References}

1. Princiotta, F.T.; Loughlin, D.H. Global climate change: The quantifiable sustainability challenge, J. Air Waste Manage. Assoc., 2014, 64(9), 979-994, doi:10.1080/10962247.2014.923351.

2. Munasinghe, M. Addressing the Sustainable Development and Climate Change Challenges Together: Applying the Sustainomics Framework. Procedia Soc. Behav. Sci. 2010, 41, 6634-6640, doi:10.1016/j.sbspro.2010.05.005.

3. Martens P.; McEvoy D.; Chang C.T. Climate Change: Responding to a Major Challenge for Sustainable Development. In Sustainability Science; Heinrichs, H., Martens, P., Michelsen, G., Wiek A., Eds.; Springer: Dordrecht, Netherlands, 2016; pp. 303-310, doi: 10.1007/978-94-017-7242-6_25.

4. Climate Change Is a Challenge For Sustainable Development. Available Online: https://www.worldbank.org/en/news/speech/2014/01/15/climate-change-is-challenge-for-sustainable-development (accessed on 25 December 2020).

5. Jonathan Feinberg. Available Online: http://mrfeinberg.com/ (accessed on 25 December 2020).

6. Benton, G.S. Carbon dioxide and its role in climate change, PNAS, 1970, 67(2), 898-899, doi:10.1073/pnas.67.2.898. 
7. Kopec, R.J. Global Climate Change and the Impact of a Maximum Sea Level on Coastal Settlement, J. Geogr., 1971, 70(9), 541550, doi:10.1080/00221347108981908

8. Frisken, W.R. Extended industrial revolution and climate change, Eos Trans. AGU, 1971, 52(7), 500-508, doi:10.1029/EO052i007p00500.

9. Lockyer, W. Does the Indian Climate Change? Nature, 1910, 84, 178, doi:10.1038/084178a0.

10. Berner, L.T.; Beck, P.S.A.; Loranty, M.M.; Alexander, H.D.; Mack, M.C.; Goetz, S.J. Cajander larch (Larix cajanderi) biomass distribution, fire regime and post-fire recovery in northeastern Siberia, Biogeosciences, 2012, 9, 3943-3959, doi:10.5194/bg-9-39432012.

11. Rayner, N.A.; Parker, D.E.; Horton, E.B.; Folland, C.K.; Alexander, L.V.; Rowell, D.P.; Kent, E.C.; Kaplan, A. Global analyses of sea surface temperature, sea ice, and night marine air temperature since the late nineteenth century, J. Geophys. Res., 2003, 108, 4407, doi:10.1029/2002JD002670.

12. Parmesan, C.; Yohe, G. A globally coherent fingerprint of climate change impacts across natural systems, Nature, 2003, 421, 3742, doi:10.1038/nature01286.

13. Kottek, M.; Grieser, J.; Beck, C.; Rudolf, B.; Rubel, F. World Map of the Köppen-Geiger climate classification updated, Meteorol. Z., 2006, 15(3), 259-263, doi:10.1127/0941-2948/2006/0130.

14. Thomas, C.D.; Cameron, A.; Green, R.E.; Bakkenes, M.; Beaumont, L.J.; Collingham, Y.C.; Erasmus, B.F.N.; de Siqueira, M.F.; Grainger, A.; Hannah, L.; Hughes, L.; Huntley, B; van Jaarsveld, A.S.; Midgley, G.F.; Miles, L.; Ortega-Huerta, M.A.; Peterson, A.T.; Phillips, O.L.; Williams, S.E. Extinction risk from climate change, Nature, 2004, 427, 145-148, doi:10.1038/nature02121.

15. Kalnay, E.; Kanamitsu, M.; Kistler, R.; Collins, W.; Deaven, D.; Gandin, L.; Iredell, M.; Saha, S.; White, G.; Woollen, J.; Zhu, Y.; Chelliah, M.; Ebisuzaki, W.; Higgins, W.; Janowiak, J.; Mo, K.C.; Ropelewski, C.; Wang, J.; Leetmaa, A.; Reynolds, R.; Jenne, R.; Joseph, D. The NCEP/NCAR 40-Year Reanalysis Project, Bull. Am. Meteorol. Soc., 1996, 77(3), 437-472, doi:10.1175/15200477(1996)077<0437:TNYRP>2.0.CO;2>.

16. Hijmans, R.J.; Cameron, S.E.; Parra, J.L.; Jones, P.G.; Jarvis, A. Very high resolution interpolated climate surfaces for global land areas. Int. J. Climatol., 2005, 25, 1965-1978, doi:10.1002/joc.1276.

17. Taylor, K.E.; Stouffer, R.J.; Meehl, G.A. An Overview of CMIP5 and the Experiment Design, Bull. Am. Meteorol. Soc., 2012, 93(4), 485-498, doi:10.1175/BAMS-D-11-00094.1

18. Phillips, S.J.; Anderson, R.P.; Schapire, R.E. Maximum entropy modeling of species geographic distributions, Ecol. Modell., 2006, 190(3-4), 231-259, doi:10.1016/j.ecolmodel.2005.03.026.

19. Tenenbaum, J.B.; de Silva, V.; Langford, J.C. A Global Geometric Framework for Nonlinear Dimensionality Reduction, Science, 2000, 2000, 2319-2323. doi:10.1126/science.290.5500.2319.

20. Vitousek, S.; Barnard, P.; Fletcher, C.; Frazer, N.; Erikson, L.; Storlazzi, C.D. Doubling of coastal flooding frequency within decades due to sea-level rise, Sci. Rep., 2017, 7, 1399, doi:10.1038/s41598-017-01362-7

21. Horton, B.P.; Rahmstorf, S.; Engelhart, S.E.; Kemp, A.C. Expert assessment of sea-level rise by AD 2100 and AD 2300, Quat. Sci. Rev., 2014, 84, 1-6, doi:10.1016/j.quascirev.2013.11.002.

22. Nunn, P.D. Responding to the challenges of climate change in the Pacific Islands: management and technological imperatives, Clim. Res., 2009, 40, 211-231, doi:10.3354/cr00806.

23. King, A.D.; Harrington, L.J. The inequality of climate change from 1.5 to $2^{\circ} \mathrm{C}$ of global warming. Geophys. Res. Lett., 2018, 45 , 5030-5033, doi:10.1029/2018GL078430.

24. Widlansky, M.J.; Timmermann, A.; Cai, W. Future extreme sea level seesaws in the tropical Pacific. Sci. Adv., 2015, 1(8), e1500560, doi:10.1126/sciadv.1500560.

25. Kuenzer, C.; Bluemel, A.; Gebhardt, S.; Quoc, T.V.; Dech, S. Remote Sensing of Mangrove Ecosystems: A Review, Remote Sens., 2011, 3, 878-928. doi:10.3390/rs3050878.

26. Levizzani, V.; Cattani, E. Satellite Remote Sensing of Precipitation and the Terrestrial Water Cycle in a Changing Climate, Remote Sens., 2019, 11, 2301, doi:10.3390/rs11192301.

27. Milesi, C.; Churkina, G. Measuring and Monitoring Urban Impacts on Climate Change from Space, Remote Sens., 2020, 12, 3494, doi:10.3390/rs12213494.

28. Gibson, J.; Anderson, D.L.; Tressler, J. Which journal rankings best explain academic salaries? Evidence from the University of California. Econ Inq,, 2014, 52, 1322-1340, doi:10.1111/ecin.12107.

29. Su, F.; Lu, C.; Cnen, W.; Bai, H.; Hwang, J.F. Capture of $\mathrm{CO}_{2}$ from flue gas via multiwalled carbon nanotubes, Sci. Total Environ., 2009, 407(8), 3017-3023, doi:10.1016/j.scitotenv.2009.01.007.

30. Herrero, M.; Havlík, P.; Valin, H.; Notenbaert, A.; Rufino, M.C.; Thornton, P.K.; Blümmel, M.; Weiss, F.; Grace, D.; Obersteiner, M. Biomass use, production, feed efficiencies, and greenhouse gas emissions from global livestock systems, PNAS, 2013, 110(52), 20888-20893, doi:10.1073/pnas.1308149110.

31. Santos, R.M.; Verbeeck, W.; Knops, P.; Rijnsburger, K.; Pontikes, Y.; Van Gerven, T. Integrated Mineral Carbonation Reactor Technology for Sustainable Carbon Dioxide Sequestration: ' $\mathrm{CO}_{2}$ Energy Reactor', Energy Procedia, 2013, 37, 5884-5891, doi:10.1016/j.egypro.2013.06.513.

32. Panepinto, D.; Genon, G.; Brizio, E.; Russolillo, D. Production of green energy from co-digestion: perspectives for the Province of Cuneo, energetic balance and environmental sustainability, Clean Techn. Environ. Policy, 2013, 15, 1055-1062, doi:10.1007/s10098-012-0568-0. 
33. Mahe, G.; Lienou, G.; Descroix, L.; Bamba, F.; Paturel, J.E.; Laraque, A.; Meddi, M.; Habaieb, H.; Adeaga, O.; Dieulin, C.; Chahnez Kotti, F.; Khomsi, K. The rivers of Africa: witness of climate change and human impact on the environment, Hydrol. Process., 2013, 27, 2105-2114, doi:10.1002/hyp.9813.

34. Ito, A.; Reyer, C.P.O.; Gädeke, A.; Ciais, P.; Chang, J.; Chen, M.; François, L.; Forrest, M.; Hickler, T.; Ostberg, S. Shi, H.; Thiery, W.; Tian, H. Pronounced and unavoidable impacts of low-end global warming on northern high-latitude land ecosystems, Environ. Res. Lett., 2020, 15(4), 044006, doi:10.1088/1748-9326/ab702b.

35. Döll, P.; Trautmann, T.; Göllner, M.; Schmied, H.M. A global-scale analysis of water storage dynamics of inland wetlands: Quantifying the impacts of human water use and man-made reservoirs as well as the unavoidable and avoidable impacts of climate change, Ecohydrology, 2020, 13, e2175, doi:10.1002/eco.2175.

36. McMichael, P. Food system sustainability: Questions of environmental governance in the new world (dis)order, Global Environ. Change, 2011, 21(3), 804-812, doi:10.1016/j.gloenvcha.2011.03.016. 